\title{
Rumo a uma nova conceituação histórica da classe trabalhadora mundial
}

Marcel van der LINDEN*

Tradução Alexandre Fortes

\begin{abstract}
RESUMO: Este artigo apresenta uma discussão historiográfica sobre o conceito de classe trabalhadora levando em conta as diversas experiências históricas desde o século XIX. A questão a ser enfocada nas páginas seguintes é como podemos visualizar um novo conceito da classe trabalhadora levando em conta as contribuições oferecidas por Breman, Gooptu, Linebaugh e outros. A fim de encontrar uma resposta a essa questão, o artigo realiza uma crítica construtiva do conceito de classe trabalhadora em Marx.
\end{abstract}

PALAVRAS-CHAVE: conceito de classe trabalhadora; História do trabalho; Karl Marx - teoria

0 conceito de "classe trabalhadora", que se originou na Europa do século XIX, tem sido questionado mais e mais nas últimas décadas. Estas críticas vêm, em parte, de acadêmicos interessados em Ásia, África e América Latina. Eles apontam que as fronteiras entre trabalho "livre" assalariado, trabalho por conta própria e trabalho compulsório não são tão claramente demarcadas, e que a oposição entre trabalho urbano e rural não deve ser tomada como absoluta. ${ }^{1}$ Jan Breman defende essa visão desde a década de 1970 nos seus estudos sobre o Gujarat contemporâneo. Em acréscimo, Nandini Gooptu demonstrou na sua pesquisa sobre os pobres urbanos em Uttar Pradesh que é plausível que essa visão seja também verdadeira para o início do século XX. ${ }^{2}$ A crítica também tem sido expressa em parte por 
historiadores da região do Atlântico no início da Era Moderna. Peter Linebaugh e Marcus Rediker traçaram um quadro fragmentário de como um proletariado multiforme de "derrubadores de matas e viajantes das águas" se desenvolveu, com vários espaços de luta: "os campos comuns, a plantation, 0 navio e a fábrica". Eles fizeram parecer provável que escravos e fugitivos da África, trabalhadores endividados da Europa, americanos nativos, assalariados "livres" e artesãos constituíam uma multidão complexa, mas também social e culturalmente interconectada, que também era vista como um todo (uma "hidra de várias cabeças") pelos donos do poder. Linebaugh e Rediker se referem à rebelião de 1791 dos escravos haitianos como a "primeira revolta bem-sucedida de trabalhadores na história moderna". Eles sugeriram que esta revolução contribuiu posteriormente para a segmentação da "multidão" rebelde: "O que ficou para trás foi nacional e parcial: a classe trabalhadora inglesa, os negros haitianos, a diáspora irlandesa." ${ }^{30}$ conceito restrito de proletariado que encontramos em $M$ arx e outros foi um resultado dessa segmentação.

A questão a ser enfocada nas páginas seguintes é como podemos visualizar um novo conceito da classe trabalhadora levando em conta as contribuições oferecidas por Breman, Gooptu, Linebaugh e outros. A fim de encontrar uma resposta a essa questão, iniciamos com uma crítica construtiva do conceito de classe trabalhadora em M arx. U samos M arx como um ponto de partida por duas razões: ele ainda é uma importante fonte de inspiração para acadêmicos de todo o mundo e, apesar de várias limitações, sua análise ainda é o que nós temos de melhor.

A COMPLEXIDADE DA MERCANTILIZAÇÃO DA FORÇA DE TRABALHO

A sentença de abertura de M arx em 0 Capital é famosa: “A 
riqueza das sociedades nas quais o modo de produção capitalista predomina aparece como uma 'imensa coleção de mercadorias'; a mercadoria individual aparece como a sua forma elementar. N ossa, portanto, começa com a análise da mercadoria.." $\mathrm{M}$ arx via - modo de produção capitalista como conseqüência da mercantilização (i) da força de trabalho, (ii) dos meios de produção e da matéria-prima, e (iii) dos produtos do trabalho. 0 primeiro elemento é crucial nesse contexto. Marx supôs que a força de trabalho pode ser mercantilizada em apenas uma forma que seria "verdadeiramente" capitalista, ou seja, via trabal ho livre assalariado, no qual o trabalhador, como "um indivíduo livre pode dispor da sua força de trabalho como sua própria mercadoria" e "não tem outra mercadoria para vender". 5 . Ele enfatizou que "a força de trabalho só pode aparecer no mercado como uma mercadoria apenas se e na medida em que seu possuidor, o indivíduo de quem essa força de trabalho é, a oferece para venda ou a vende como uma mercadoria". 6

0 conceito restrito de classe trabalhadora baseia-se nessa idéia. Se apenas a força de trabalho dos trabalhadores livres assalariados é mercantilizada, a classe trabalhadora "real" no capitalismo consiste nesses trabalhadores. A hipótese de Marx, até onde sabemos, nunca foi sustentada por uma elaboração adequada. Ela provavelmente pareceu auto-evidente por muito tempo, porque parecia corresponder ao processo pelo qual 0 proletariado se formou na Região do Atlântico Norte. Todavia, a hipótese de $M$ arx se baseia em dois pressupostos dúbios, ou seja, que a força de trabalho, deve ser oferecida para venda pela pessoa que é o portador e o possuidor dessa força de trabalho, e que a pessoa que vende a força de trabalho o faz exclusivamente. ${ }^{7}$ Por que deveria ser assim? Por que a força de trabalho não pode ser vendida por outro que não o portador? Por que a pessoa que oferece a força de trabalho (a sua própria ou a de outrem) à venda não a vende condicionalmente, junto com meios de 
produção? E por que um escravo não pode executar um trabalho contratado por uma terceira parte em benefício de seu proprietário? Se nós só nos detemos na distinção entre um "portador" e um "possuidor" de força de trabalho enquanto tal, podemos já distinguir os quatro tipos de mercantilização da força de trabalho, a saber, mercantilização autônoma, na qual o portador da força de trabalho é também o possuidor, e mercantilização heterônoma, na qual o portador da força de trabalho não é o possuidor; em ambos os casos, a força de trabalhado do portador pode ser oferecida pelo próprio portador ou por outra pessoa (Tabela 1).

TABELA 1 - Algumas formas de mercantilização do trabalho

Autônoma
(o portador é o possuidor)

Heterônoma
(o portador não é o
possuidor)

O portador vende a sua Trabalho livre assalariado Trabalho assalariado de própria força de trabalho (Marx)

Parceria

Trabalho de artesãos por

conta própria

O portador não vende a Trabalho sua própria força de subcontratado trabalho assalariado Trabalho de escravos de plantel

Trabalho assalariado de crianças

Parece ser razoável postular que a mercantilização tenha muitas formas, das quais o trabalho livre assalariado seja apenas um exemplo. ${ }^{8}$ Exploraremos essas múltiplas formas abaixo, tanto apontando formas transitórias entre as classes subalternas de M arx quanto trazendo à luz alguns de seus postulados implícitos falsos. Esperamos que essa desconstrução prepare o terreno para uma nova conceituação. 


\section{TRANSIÇÕES GRADUAIS}

Além de capitalistas e senhores de terras, a tradição marxiana distingue cinco classes ou semiclasses subalternas no capitalismo: os trabalhadores assalariados livres, que apenas possuem a sua força de trabalho e a vendem; a pequena burguesia, consistindo em pequenos produtores e distribuidores de mercadoria; os trabalhadores por conta própria, que possuem sua força de trabalho e meios de produção e vendem os produtos do seu trabalho ou serviços ("o trabalhador por conta própria é o seu próprio trabalhador assalariado, seus meios de produção próprios aparecem para ele como capital. Como seu próprio capitalista ele emprega a si mesmo como seu próprio trabalhador assalariado"19); os escravos, que nem possuem sua própria força de trabalho nem suas ferramentas e são vendidos (na escravidão "o trabalhador não é nada mais do que uma máquina de trabalho viva, que portanto tem um valor para os outros, ou antes é um valor". ${ }^{10}$ ); e o lumpem-proletariado, que não é vendido e não vende nada. 0 último grupo usualmente permanece fora da análise e é usado principalmente como uma categoria residual.

A luta de classes é travada principalmente entre capitalistas, senhores de terras e assalariados. As outras classes são historicamente menos importantes; elas "decaem e finalmente desaparecem em face da moderna indústria". ${ }^{11}$

- A escravidão é "uma anomalia oposta ao próprio sistema burguês", que é "possível em pontos individuais do sistema burguês de produção", mas "apenas porque ela não existe em outros pontos". ${ }^{12}$

- $\quad$ Trabalhadores por conta própria são anomalias que existem na pequena agricultura de base familiar (em conexão com a indústria doméstica). ${ }^{13}$ 
- A pequena burguesia, os pequenos vendedores, lojistas e rentiers, os artesãos e camponeses, todos afundam gradualmente no proletariado. ${ }^{14}$

- $\quad$ O lumpem-proletariado é “a 'classe perigosa', o lixo social, aquela massa passivamente apodrecida que se desprende das camadas mais baixas da velha sociedade", ${ }^{15}$ o que inclui "vagabundos, criminosos e prostitutas". ${ }^{16}$

De acordo com esse esquema marxiano, há uma lacuna entre os trabalhadores assalariados livres e os outros grupos subalternos. M as esse esquema em alguma medida coincide com a realidade histórica? Os trabalhadores assalariados livres de M arx realmente existem? Argumentaríamos que há uma quase infindável variedade de produtores no capitalismo e que as formas intermediárias entre as diferentes categorias são vagas e fluidas.

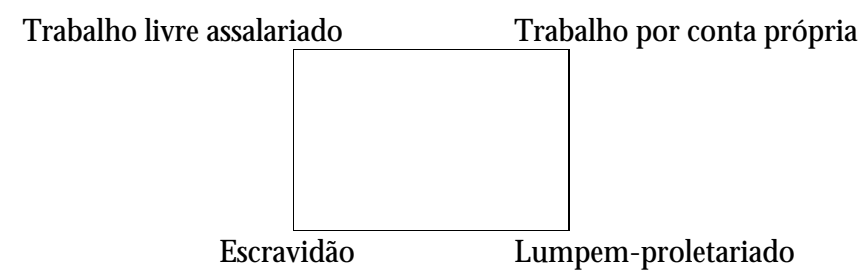

Talvez seja útil olhar mais de perto algumas dessas formas intermediárias; entre o trabalho assalariado e escravidão; entre trabalho assalariado e por conta própria; entre escravidão e trabalho por conta própria; e entre trabalho assalariado, escravidão e trabalho por conta própria, de um lado, e o lumpem-proletariado de outro.

Formas intermediárias entre trabalho assalariado e escravidão. Há várias relações de trabalho nas quais o(a) assalariado(a) é forçado(a) fisicamente a fazer o seu trabalho, seja 
quando o seu salário é pago ou quando é entregue para uma terceira pessoa. Trabalho infantil, no qual os pais ou guardiões recebem os salários, é um bom exemplo. Jovens garotas japonesas que são empregadas como gueishas em troca por uma quantia em dinheiro são um exemplo disso. ${ }^{17}$ São conhecidos muitos casos de escravos que desempenham trabalho assalariado para os seus senhores. Em Buenos Aires, no fim do século XVIII, por exemplo, esse fenômeno era tão comum que muitos proprietários de escravos eram completamente dependentes dos salários dos seus escravos. Os registros cartoriais da época sugerem que "em contratos de trabalho mais longos, os salários, menos os custos da sua manutenção, eram pagos diretamente aos proprietários de escravos pelos empregadores do trabalho escravo contratado". ${ }^{18}$ Talvez seja útil distinguir três variedades:

- $\quad$ o proprietário do escravo compele o escravo a prestar trabalho assalariado para outro empregador e recolhe todo ou parte dos salários. Freqüentemente, "os proprietários de escravos e os empregadores dos escravos combinam a taxa de emprego por cabeça de escravo", mas "a situação de um escravo buscando ativamente e negociando o seu emprego ocorria do mesmo modo". ${ }^{19}$

- $\quad 0$ proprietário de escravos paga aos seus escravos, ou às suas escravas, em dinheiro por um esforço extra, seja por meio de "bônus, seja com presentes ou então como um incentivo", seja "um pagamento feito por trabalho extra num sistema de tarefas ou por trabalhar além do tempo usual". ${ }^{20}$

- $\quad 0$ escravo trabalha voluntariamente por seus salários, para um empregador ou para um colega escravo. A fazenda Blue M ountain, na Jamaica, no final do século XVIII, é um exemplo do último caso: "os escravos pagavam salários uns aos outros. Trabalho dominical nas culturas de subsistência, por exemplo, poderia render 1s.8d (um xelim 
e oito dimes) por dia mais o café da manhã" ${ }^{21}$ É claro que esta última variedade em particular torna consideravelmente difusa a distinção entre um assalariado e um escravo.

Inversamente, os trabalhadores assalariados são freqüentemente menos livres do que a visão clássica sugere. Os empregadores freqüentemente restringem a liberdade dos seus trabalhadores de partirem em caso de escassez de mão-de-obra. Um empregado pode ser amarrado a um empregador de muitas maneiras:

- A escravidão por dívidas é um método que ocorre em todos os continentes, das minas de carvão escocesas no século XVIII à agricultura contemporânea na América Latina e no Sul da Ásia. ${ }^{22}$

- $\quad 0$ trabalho endividado é certamente intimamente relacionado à escravidão por dívida. Os coolies indianos, javaneses e chineses, que eram empregados na África do Sul, na América Latina e nas outras partes da Ásia ,são um exemplo bem conhecido disso. ${ }^{23}$

- A mobilidade dos trabalhadores também pode ser limitada pela exigência de certificados de liberação. Sem esses meios de identificação, os trabalhadores não podem ser empregados por nenhum empregador. Era uma característica típica dessa prática que 0 empregador tomasse posse do certificado ao empregar o trabalhador e 0 devolvesse apenas quando ele ou ela tivesse, na visão do empregador, satisfeito todas as suas obrigações. ${ }^{24}$

- A compulsão física era uma outra opção para os empregadores. Algumas vezes os empregadores chegavam a ponto de trancar os seus empregados assalariados, prevenindo-os de serem "tentados" por seus rivais nos negócios. Na indústria têxtil japonesa da década de 1920, as 
trabalhadoras eram trancadas em dormitórios por essa razão. Às vezes, elas não tinham permissão de deixar as instalações por mais de quatro meses. ${ }^{25}$

- $\quad$ Programas de seguridade social e outros oferecem uma forma menos agressiva de reter os empregados. Em torno de 1900, as companhias argentinas, por exemplo, criavam sociedades fraternais e de ajuda mútua que eram dirigidas pela companhia e concebidas para tornar 0 trabalhador dependente da firma. ${ }^{26} \mathrm{H}$ ortas providenciadas pela companhia poderiam ter o mesmo efeito, porque elas tornavam possível uma suplementação salarial, seja porque as verduras, frangos e outros produtos domésticos reduziam o custo de vida, ou porque a produção dessas hortas era comprada pelo empregador. ${ }^{27}$

- $\quad$ Finalmente, as conexões entre um empregador e um empregado fora da relação imediata de emprego poderiam ter um efeito vinculante. (D esenvolveremos isso abaixo.)

Formas intermediárias entre trabalho assalariado e por conta própria.Na visão clássica, os trabalhadores só dispõem da sua força de trabalho, mas não de meios de produção. Há muitas exceções a esta regra.

- $\quad$ Um exemplo é o trabalhador que leva suas próprias ferramentas à oficina, como era e ainda é comum em muitos lugares. Já na década de 1880, o economista alemão August Sartorius von Waltershausen observou nos Estados Unidos que "ao contrário das suas contrapartes européias, os trabalhadores fabris americanos usualmente possuem suas próprias ferramentas. [...] As ferramentas freqüentemente constituem uma proporção considerável da riqueza de um trabalhador". ${ }^{28}$

- Uma segunda possibilidade é que os trabalhadores 
tenham que tomar emprestados os seus meios de produção do empregador. N este caso, eles pagam uma caução e são formalmente independentes. Os puxadores de carruagem em Changsha, província de Hunan, China, em torno de 1918 são um exemplo disso. Suas carruagens eram propriedades de "garagens" (che-zhan) e tinham que ser alugadas a cada dia. 0 dono da garagem pagava os impostos da carruagem e o puxador tinha que fazer um depósito de dez dólares mexicanos (de prata). "Cada carrinho tinha um número e era atribuído a um determinado puxador, que era sempre responsável por ele." Se a carruagem se quebrasse e fosse retirada para reparos, 0 aluguel diário ainda tinha que ser pago. ${ }^{129} \mathrm{~A}$ renda do puxador consistia na diferença entre o que ele recebia e os seus pagamentos ao proprietário da garagem.

- Também ocorria que fosse permitido a um empregado ficar com parte do produto do seu trabalho e vendêlo independentemente. Os mineiros da prata em Pachuca (M éxico), em meados do século XVIII, recebiam uma soma em dinheiro (salários) por uma quantia básica do veio de prata, e tudo o que eles produzissem em excesso era dividido em duas partes: "dessa metade, o apanhador dava uma certa proporção aos carregadores, carpinteiros e outros trabalhadores da mina que o tinham ajudado". ${ }^{30}$ Sabemos que arranjos similares existiram na agricultura em Java e em muitas outras partes. ${ }^{31}$

Formas intermediárias entre escravidão e trabalhado por conta própria. O caso de Simon Gray, um escravo do Sul dos Estados Unidos, que serviu como 0 barqueiro-chefe da companhia madeireira Natchez de 1845 até 1862, demonstra quão complicada a realidade capitalista pode ser. A tripulação de Gray normalmente contava com dez a vinte homens e se 
constituía tanto de escravos afro-americanos quanto de brancos ribeirinhos. "Alguns dos escravos eram de propriedade da companhia, enquanto outros, como o próprio Gray, eram contratados de outros proprietários pela firma. Os tripulantes brancos, por outro lado, eram empregados pelo negro, que mantinha os seus registros, pagava suas despesas, Ihes emprestava dinheiro, e às vezes Ihes pagava salários. Conseqüentemente, eles viam Gray como seu empregador." Gray e os seus homens com freqüência ficavam longe de casa por duas ou três semanas. Durante estas viagens, Gray desempenhava uma grande quantidade de tarefas gerenciais. "Além de fazer entregas ele também pegava encomendas para a fábrica, cotava preços, concedia crédito aos consumidores e cobrava o dinheiro devido à companhia madeireira." ${ }^{32}$ Assim, esse caso mostra um escravo que funcionava como gerente, trabalhadores livres que eram empregados por um escravo, e outros escravos que tinham que obedecer a esse empregador. Nem todos os escravos eram propriedade da companhia $\mathrm{N}$ atchez, mas al guns, incluindo Gray, eram empregados de outros proprietários de escravos. Essa situação é, sem dúvida, incomum de um ponto de vista histórico. Em outra situação, escravos trabalhavam como parceiros. $\mathrm{Na}$ Jamaica, no final do século XVIII, às vezes ocorria a situação em que "os escravos 'bem de vida' estabeleciam terras de cultivo e usavam os 'mais pobres' para trabalhar para eles em troca de uma parcela da produção".

Formas intermediárias entre trabalho assalariado, escravidão no trabalho por contra própria e o lumpem-proletariado. A transição das três formas principais (escravidão, etc.) para a "não-classe" do lumpem-proletariado também é gradual. V. L. Allen defendeu que "em sociedades nas quais a luta pela sobrevivência é a norma para uma alta proporção de toda a classe trabalhadora, e nas quais homens, mulheres e crianças são compelidos a buscar meios alternativos de subsistência, distintos 
dos seus tradicionais, o lumpem-proletariado mal se distingue da maior parte do restante da classe trabalhadora". ${ }^{34}$

- $\quad$ Trabalhadores "respeitáveis" destituídos também se sentem compelidos a roubar. Saques de comida organizados por trabalhadores eram um "fenômeno de escala nacional" nos Estados U nidos em 1932. ${ }^{35}$ Tais saques reapareceram na I tália no começo dos anos $1970 .{ }^{36}$

- Catar no lixo também ocorre com freqüência em tempos difíceis e pode até mesmo se tornar lei costumeira. Louis Adamic registrou em 1935 que "desde quando qualquer um nos campos antracitos da Pensilvânia se recorda, era costumeiro que os mineiros e suas famílias fossem com sacos ou barris aos depósitos de resíduos que cercavam suas vilas insalubres apanhar carvão entre as rochas e lascas descartadas nos processos de quebra e limpeza das grandes carvoarias. Os catadores eram usualmente das famílias mais pobres". ${ }^{37}$

- $\quad$ O roubo, o desvio de dinheiro e o furto são atividades "normais" para certos grupos de trabalhadores. É comum entre doqueiros em muitos países roubar uma parte de um carregamento, mas em fábricas e escritórios tais roubos por empregados dos escalões inferiores também ocorrem freqüentemente. ${ }^{38}$

\section{POSTULADOS IMPLÍCITOS}

A visão clássica, além de fazer distinções drásticas entre fenômenos que na realidade não são entidades fixas, também assume postulados implícitos que têm que ser examinados. Um grande número desses postulados se origina na idéia de que os trabalhadores trocam a sua força de trabalho por dinheiro e então compram alimentos com esse dinheiro. Ao consumir esses bens, eles reproduzem sua força de trabalho, que podem então 
vender novamente ao empregador. Assim, no nível da circulação, há um processo cíclico, que é demonstrado pelo seguinte diagrama:

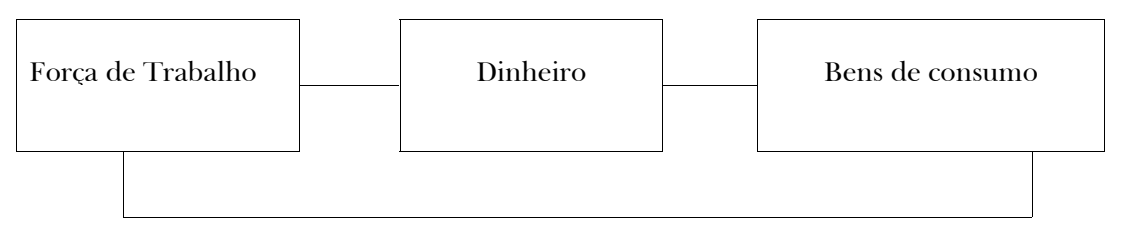

Esse conceito de circulação é uma abstração de muitos elementos e sugere um processo complexo e isolado. Em primeiro lugar, ele sugere que o consumo dos salários recebidos pelo empregado não requer trabalho. A compra de bens de consumo e o esforço para torná-los aptos a serem consumidos (por exemplo, vender e preparar comida, ou alugar e manter limpo um lugar para viver) não são levados em conta. As feministas, todavia, têm apontado por décadas que o trabalho assalariado não pode existir sem 0 trabalho de subsistência. ${ }^{39}$ Esporadicamente, há empregados que reproduzem a sua força de trabalho sem trabalho de subsistência, mas estas são pessoas com um renda muito alta: "o proletário real que reproduz sua força de trabalho completamente por meio do seu salário pago por seu trabalho é, no máximo, o Yuppie (corruptela para a expressão Young Urban Professional, ou seja, "jovem profissional urbano" em inglês), que como um executivo de mobilidade ascendente de uma firma multinacional compra um sanduíche para o almoço e encontra sua esposa Yuppie (quem sabe, uma corretora do mercado de ações ou uma professora universitária) à noite em um restaurante para jantar, enquanto uma empregada doméstica limpa o seu apartamento alugado. 0 trabalhador assalariado normal, todavia, se reproduz como uma dona-de-casa ou 
participa ativamente da produção da subsistência. ${ }^{40} \mathrm{Na}$ maioria dos casos, o trabalho de subsistência é feito por uma ou mais mulheres no núcleo doméstico, a esposa ou as esposas, e às vezes as filhas do paterfamilias. Também é possível que 0 próprio assalariado empregue um ou mais assalariados que façam 0 trabalho doméstico. Muitas famílias brancas da classe trabalhadora na África do Sul do começo do século XX, por exemplo, tinham uma empregada doméstica negra, que, entre outras coisas, era responsável por "fazer o fogo, limpar o fogão, varrer, lavar pratos, preparar o chá da manhã e da noite, manter o quintal limpo, e fazer o trabalho de rotina na horta, tal como capinar e regar". ${ }^{41}$

Em segundo lugar, o diagrama parece sugerir que a relação entre empregador e empregado se limita à troca de dinheiro por força de trabalho. Laços possíveis entre ambas as partes fora do processo de circulação não são levados em consideração. Mas, com certeza, esses laços podem existir. 0 empregador pode prender 0 empregado economicamente, por exemplo, ao proporcionar alojamento de propriedade da companhia ou ao tornar obrigatório ao empregado comprar bens de consumo que o empregador oferece para venda com a renda recebida como salário (o chamado "sistema de barracão", ou truck system). ${ }^{42} \mathrm{M}$ as a relação entre 0 empregador e 0 empregado não é necessariamente econômica; por exemplo, se há laços familiares entre ambos, ou se eles pertencem à mesma comunidade religiosa. Casos de habitação da companhia e outras formas de vínculo material podem ser encontrados especialmente, mas por certo não exclusivamente em grandes companhias, como por exemplo a United Fruit Company, que abrigava os seus campesinos na América Central nas plantations, ou a siderúrgica Krupp na Alemanha. ${ }^{43}$ É provável que vínculos não-econômicos sejam relativamente mais comuns em pequenas companhias. 
Em terceiro lugar, o diagrama cíclico sugere que um empregado ou uma empregada tem apenas um empregador e que ele ou ela apenas se envolve em uma relação de trabalho de cada vez. Este fenômeno de fato ocorre freqüentemente e é comum entre artesãos e trabalhadores qualificados, mas este não é o caso para uma grande parte da população mundial dependente de salários, nem no passado, nem no presente. Pessoas com vários empregos são muito comuns na Ásia, África e América Latina. 0 mesmo era verdade para a Europa nas décadas anteriores à ascensão do Estado de bem-estar. É verdade novamente para a Rússia contemporânea, onde ao menos cerca de 15 a $20 \%$ da população empregada tinha um emprego suplementar em meados da década de $1990 .{ }^{44}$ Por certo, também é perfeitamente possível que o empregado tenha diferentes tipos de renda. André Gunder Frank falou corretamente da "fluidez na relação trabalhador-proprietário". Ele dá o exemplo de "um único trabalhador que é simultaneamente: (i) proprietário das suas próprias terra e casa, (ii) parceiro na terra de outro (às vezes pela metade, às vezes por um terço da colheita), (iii) arrendatário na terra de uma terceira pessoa, (iv) trabalhador assalariado durante a época da colheita numa dessas terras, e (v) vendedor independente das suas próprias mercadorias domésticas". ${ }^{45} \mathrm{~A}$ importância relativa de diferentes fontes de renda pode mudar repetidamente ao longo do tempo, como Adam Smith já sabia. ${ }^{46}$

Em quarto lugar, o modelo da circulação enfoca a relação entre um empregador e o seu empregado ou a sua empregada. Mas é perfeitamente possível que os trabalhadores sejam empregados como um grupo por um empregador. Às vezes isto é feito por meio de um intermediário que recruta trabalhadores na área circundante e subseqüentemente os coloca à disposição do empregador. $\mathrm{Na}$ indústria têxtil de Xangai, no começo do século $X X$, por exemplo, havia o sistema pao-kung no qual 0 intermediário "contratava" meninas nas vilas vizinhas por três 
anos, dos seus pais, e então "as empregava" nos cotonifícios britânicos e japoneses na cidade durante aquele período. ${ }^{47} \mathrm{Em}$ outro arranjo, o intermediário supervisionava os trabalhadores por ele recrutados, e deste modo trabalhava ele próprio para o seu cliente. Este era, por exemplo, o caso em muitas minas de carvão indianas e chinesas. ${ }^{48}$ Poderia também ocorrer que um grupo de trabalhadores se oferecia para a contratação por um empregador sem a mediação de um intermediário, como no caso dos trabalhadores nas colheitas operando na parte européia da Rússia no século XIX, que se organizavam em artels ("cooperativas"). ${ }^{49}$

Em quinto lugar e finalmente, de acordo com o modelo, 0 ciclo se quebra quando o trabalhador não mais oferece sua força de trabalho para venda e pára de trabalhar. Isto sugere que as greves são uma forma de ação coletiva especialmente associada aos trabalhadores assalariados livres, e também que esta é a única forma possível de ação. M as se verificarmos os modos nos quais o protesto é expresso e a pressão é exercida pelos diferentes grupos de trabalhadores subalternos (ou seja, os escravos, os trabalhadores por conta-própria, o lumpem-proletariado e os trabalhadores assalariados "livres"), parece haver uma considerável interseção. No passado, todos os tipos de trabalhadores foram à greve. Os mineiros de prata parceiros em Chihuahua, por exemplo, protestavam já na década de 1730 contra 0 encerramento dos seus contratos de trabalho pelos proprietários da mina, entrincheirando-se nas serras circundantes. "Lá eles construíram uma barricada improvisada de pedra, desfraldaram uma bandeira proclamando seu desafio e juraram atormentar a vila de San Felipe, matar o proprietário da mina, San Juan y Santa Cruz, e queimar sua casa até o chão. Nas várias semanas seguintes eles se recusaram a abandonar seu reduto nas montanhas, onde passavam o tempo compondo e cantando canções de protesto. ${ }^{\prime 50}$ Os mineiros retornaram apenas 
após a mediação de um padre enviado pelo bispo. Escravos também iam à greve regularmente. $N$ as plantations do início do século XIX no Caribe britânico, por exemplo, havia movimentos paredistas unilaterais. "As rebeliões de Demerara em 1829 e em 1831, ambas começaram como versões de greves modernas, acompanhadas por atos de desafio, mas não por assassinatos. Apenas quando a milícia real retaliou com força, assumindo que se tratava de um outro levante armado, foi que tal ocorrência realmente se deu." ${ }^{51}$ No sentido oposto, trabalhadores livres assalariados usaram métodos de ação que são usualmente associados com outros grupos de trabalhadores subalternos, tais como linchamentos, motins, ataques incendiários e com explosivos. $^{52}$

\section{RUMO A NOVOS CONCEITOS}

As reflexões acima demonstram como as fronteiras entre os trabalhadores assalariados "Iivres" e outros tipos de trabal hadores subalternos na sociedade capitalista são vagas e graduais. Em primeiro lugar, há áreas cinza extensas e complicadas de posicionamentos transitórios entre os trabal hadores assalariados "livres" e os escravos, os trabalhadores por conta própria e os lumpem-proletários. Em segundo lugar, quase todos os trabalhadores pertencem a núcleos domésticos que combinam vários modos de trabalho. ${ }^{53} \mathrm{Em}$ terceiro lugar, trabalhadores subalternos individuais podem também combinar diferentes modos de trabalho tanto sincrônica quanto diacronicamente. $\mathrm{E}$, finalmente, a distinção entre os diferentes tipos de trabalhadores subalternos não é tão precisamente delimitada. As implicações são de longo alcance. Aparentemente, há uma grande classe de pessoas dentro do capitalismo cujo trabalho é mercantilizado de muitas formas. Nesse contexto, referimo-nos a essa classe como trabalhadores subalternos. Eles constituem um grupo muito 
variado, que inclui escravos de plantel, parceiros, pequenos artesãos e assalariados. É a dinâmica histórica dessa "multidão" que gostaríamos de entender.

A primeira questão que capta a nossa atenção é o que todos esses diferentes trabalhadores subalternos têm em comum. Onde está a linha divisória, a fundamentum divisionis, entre eles e 0 outro lado, daqueles que têm mais poder? Tomando uma expressão de Cornelius Castoriadis como uma primeira guia, poderíamos dizer que todos os trabalhadores subalternos estão num estado de "heteronomia institucionalizada". Para esse filósofo greco-francês, a heteronomia institucionalizada é o oposto da autonomia social: ela se manifesta como "uma massa de condições de privação e opressão, como uma estrutura institucional solidificada, global e material, da economia, do poder e da ideologia, como indução, mistificação, manipulação e violência". A heteronomia institucionalizada expressa e sanciona "uma divisão antagônica da sociedade e, em convergência com ela, o poder, uma categoria social determinada sobre o conjunto. [...] Desse modo, a economia capitalista, produção, distribuição, mercado, etc. é alienante na medida em que ela implica a divisão da sociedade em proletários e capitalistas". ${ }^{54}$ Podemos nos tornar um pouco mais específicos quando seguimos uma indicação do filósofo Gerald Cohen. Ele tem argumentado que "a falta de meios de produção não é tão essencial ao status de proletário quanto tradicionalmente se diz. É melhor dizer que um proletário deve vender sua força de trabalho a fim de obter seus meios de vida. Ele pode possuir meios de produção, mas não pode usá-los para se sustentar salvo estabelecendo um contrato com um capitalista" ${ }^{55}$ Seguindo M arx, Cohen compreende a frase "deve vender sua força de trabalho" nesse contexto como compulsão econômica, mas se nós também incluirmos a compulsão física, chegaremos próximos de uma clara demarcação. I Todo possuidor de força de trabalho cuja força de trabalho é vendida ou empregada 
por outra pessoa sob compulsão econômica ou não-econômica pertence à classe dos trabalhadores subalternos, não importando se 0 portador ou a portadora da força de trabalho vende por si mesma, ou por si mesma, e não importando se o portador ou a portadora possui meios de produção. Num certo sentido, isso nos leva de volta ao conceito pré-marxiano de "classes trabalhadoras". Todos os aspectos dessa definição provisória requerem mais pesquisa. ${ }^{56}$

Uma outra questão se segue à anterior: Como podemos conceituar as diferenciações internas da classe subalterna? Como é bem conhecido, a análise clássica enfocou no poder o processo de produção. 0 processo de produção é certamente caracterizado por uma combinação de três elementos: "atividade proposital, que é o trabalho em si mesmo, o objeto sobre o qual o trabalho é exercido, e os instrumentos do trabalho". ${ }^{57} 0$ produto do trabalho é o quarto elemento dessa análise. Juntos esses elementos definem as mais importantes dimensões da análise clássica que deve ser mantida em uma abordagem modificada:

i A relação entre o empregado ou a empregada e a sua força de trabalho (o empregado ou a empregada está em controle do seu corpo, ou quem o controla é o empregador ou uma terceira parte?);

ii A relação entre o empregado ou a empregada e os seus meios de produção (em que extensão o empregado ou a empregada possui os seus objetos e instrumentos de trabalho e em que extensão esses objetos e instrumentos são possuídos pelo empregador ou por uma terceira parte?);

iii A relação entre o empregado ou a empregada e os produtos do seu trabalho (em que extensão o resultado do seu esforço pertence ao empregado ou à empregada e em que extensão ele pertence a um empregador ou a uma terceira parte?).

As observações neste artigo parecem sugerir que, ao lado 
das dimensões clássicas, três dimensões adicionais são relevantes:

iv A relação entre o empregado ou a empregada e outros membros do seu núcleo doméstico (que tipo de dependência social e econômica existe entre o empregado e os outros membros do núcleo doméstico?);

$\checkmark$ A relação entre o empregado ou a empregada e o seu empregador fora do processo imediato de produção (em que extensão o empregado está vinculado por meio de débitos, moradia, etc. ao empregador?);

vi A relação entre o empregado e outros empregados dentro da relação de trabalho (que tipo de dependência social e econômica existe entre o empregado ou a empregada e seus colegas imediatos?). ${ }^{58}$

Estas seis dimensões nos permitem desenvolver um arco de sutis variações no qual podemos descrever a posição de empregado individual vis-à-vis um empregador. ${ }^{59}$ Se um empregado combina vários empregos, então temos que levar a cabo várias dessas determinações de classe. Além disso, já que um empregado em geral pertence a uma unidade mais ampla (núcleo doméstico), parece aconselhável estender a análise mais além e incluir a posição de classe dos outros membros desse núcleo doméstico. Isto pode levar a incongruências interessantes se um núcleo doméstico une posições de classe divergentes. ${ }^{60}$ Finalmente, essas análises deveriam na medida do possível ser feitas longitudinalmente, porque todos os membros do núcleo doméstico podem mudar de "emprego" no curso de suas vidas, isto é, se eles têm um certo grau de liberdade. ${ }^{61}$

U ma nova tipologia poderia levar adiante a diferenciação das variáveis distinguidas na Tabela 1 . Nós poderíamos, por exemplo, distinguir três tipos de transações de venda da força de trabalho conforme se eles concernem exclusivamente força de trabalho, ou também envolvem parte dos meios de produção ou os meios de produção como um todo. Deveríamos também levar 
em consideração como o trabalho é pago. Immanuel Wallerstein uma vez sugeriu uma tipologia rudimentar, consistindo em dois grupos principais: aqueles que precisam renunciar a todo valor do que produzem, e aqueles que precisam renunciar a parte desse valor. Ambos os grupos podem ser subdivididos ainda mais naqueles que não recebem nada, recebem bens ou dinheiro, ou bens mais dinheiro em troca. Desse modo, uma matriz pode ser formada com oito categorias, das quais apenas uma consiste EM trabalhadores assalariados "típicos". ${ }^{62}$ Poderíamos incorporar esta sugestão também. ${ }^{63}$

$M$ as qualquer que seja o modo em que venhamos a lidar com isso, para nós vários alertas parecem ser justificáveis. Em primeiro lugar, devemos resistir à tentação de uma "grande teoria" empiricamente vazia (C. Wright Mills): em vez disso, precisamos criar tipologias com base no conhecimento empírico detalhado. Em segundo lugar, não devemos estudar os diferentes tipos de trabalhadores subalternos separadamente, mas considerar as conexões entre eles tanto quanto possível. Sidney Mintz, por exemplo, nos precaveu a não definir "escravo" e "proletário" isoladamente: "[Essas] duas vastas categorias de labutadores eram de fato intimamente ligadas pela economia mundial que tinha dado origem a ambas na sua forma moderna." Devemos levar em conta tais elos, já que "uma abordagem puramente conceitual deixa algo a desejar". ${ }^{64} \mathrm{Em}$ terceiro lugar, não devemos ver os subalternos como indivíduos isolados porque, na realidade, eles têm que ser analisados antes como seres humanos concretos, que são parte de famílias, sistemas de parentesco e outras redes sociais e culturais. $E$, finalmente, não devemos olhar os subalternos basicamente do ponto de vista do Estado nacional (como em "a classe trabalhadora indiana", etc.); é melhor ver o aspecto "nacional" como algo que tem que ser contextualizado e explicado em si mesmo. Breman e outros nos fazem confrontar uma questão ampla e complexa. 
LINDEN, Marcel van der. Towards a New Historical Conceptualization of the World Working Class. História, São Paulo, v.24, n.2, p.11-40, 2005.

ABSTRACT: This article presents an historiographical discussion about the working class concept, dealing with the historical experiences since XIX century. The question addressed in the following pages is what a new concept of the working class might look like that would take into account the insights offered by Breman, Gooptu, Linebaugh and others. In order to find an answer to this question, it starts off with a constructive critique of Marx' concept of the working class.

KEYWORDS: working class concept; labour History; Karl Marx theory.

NOTAS

\footnotetext{
* Research Diretor do International Institute of Social History - Amsterdam University, CEP 1019 AT, Holanda. e-mail: mvl@iisg.nl.

${ }^{1}$ V.L. Allen foi um dos primeiros a iniciar essa discussão em "The Meaning of the Working Class in Africa”, Journal of Modern African Studies, v.10, n.2, p.169189, 1972. Ver também BERGQUIST, Charles. Labor in Latin America. Comparative Essays on Chile, Argentina, Venezuela, and Colombia. Stanford: Stanford University, 1986, especialmente os capítulos 1 e 6.

${ }^{2}$ BREMAN, Jan. Patronage and Exploitation. Changing Agrarian Relations in South Gujarat. Berkeley: University of California, 1974; __. Of Peasants, Migrants and Paupers. Rural Labour Circulation and Capitalist Production in West India. Nova Déli: Oxford University, 1985; Beyond Patronage and Exploitation. Changing Agrarian Relations in South Gujarat. Nova Déli: Oxford University, 1993); __. Footloose Labour. Working in India's Informal Economy. Cambridge: Cambridge University, 1996; GOOPTU, Nandini. The Politics of the Urban Poor in Early Twentieth-Century India. Cambridge: Cambridge University, 2001.

${ }^{3}$ LINEBAUGH, Peter \& REDIKER, Marcus. The Many-Headed Hydra. Sailors, Slaves, Commoners, and the Hidden History of the Revolutionary Atlantic. Boston: Beacon Press, 2000, p.327, 319, 286.

${ }^{4}$ MARX, Karl. Capital. v.1. Trad. Ben Fowkes. Harmondsworth: Penguin, 1976, p.125.
} 
${ }^{5}$ Idem, p.272.

${ }^{6}$ Idem, p.271.

7 O termo "venda" não é realmente apropriado no caso do trabalho assalariado, porque é sempre uma venda temporária, e usualmente nós não nos referimos a essa transação como "venda", mas como "contratação". Isso parece uma diferença fútil mas as implicações teóricas podem ser grandes. Ver OPPENHEIMER, Franz. Die soziale Frage und der Sozialismus. Eine kritische Auseinandersetzung mit der marxistischen Theorie. Jena: Verlag von Gustav Fischer, 1912, p.119-122; ELDRED, Michael \& HANLON, Marnie. "Reconstructing Value-Form Analysis". Capital and Class, Spring, n.13, p.24-60, 1981, p.44; LUNDKVIST, Anders. "Kritik af Marx' lønteori", Kurasje, n.37, p.15-46, dec., 1985, p.16-18; BURKHARDT, Michael. "Kritik der Marxschen Mehrwerttheorie". Jahrbuch für Wirtschaftswissenschaften, n.46, p.121-137, 1995, p.125-127; e RUBEN, Peter. "Ist die Arbeitskraft eine Ware? Ein Beitrag zu einer marxistischen Marxkritik". In: EIDAM, Heinz \& SCHMIED-KOWARZIK, Wolfdietrich (ed.). Kritische Philosophie gesellschaftlicher Praxis. Würzburg: Königshausen \& Neumann, 1995, p.167-183.

${ }^{8}$ John Hicks já chegou à conclusão de que há várias formas de mercantilização da força de trabalho: "Tanto o trabalhador pode ser vendido de uma vez por todas, o que é escravidão; ou seus serviços podem ser contratados, o que é pagamento de salário". HICKS, John. A Theory of Economic History. Oxford, 1969, p.123. Uma primeira elaboração dessa visão pode ser encontrada em ROHWER, Götz. "Kapitalismus und 'freie Lohnarbeit'. Überlegungen zur Kritik eines Vorurteils". in: Hamburger Stiftung zur Förderung von Wissenschaft und Kultur (ed.), "Deutsche Wirtschaft". Zwangsarbeit von KZHäftlingen für Industrie und Behörden. Hamburg: VSA-Verlag, 1991, p.171185 .

9 MARX, Karl. Ökonomische Manuskripte 1863-1867. In: Marx-Engels Gesamtausgabe. 2.ed. v.II/4.1. Berlin: Dietz, 1988, p.111.

10 MARX, Karl. Grundrisse. of the Critique of Political Economy (Rough Draft). Traduzido com um prefácio de Martin Nicolaus. Harmondsworth: Penguin, 1973, p.465.

${ }^{11}$ Manifesto of the Communist Party. In: MARX, Karl. The Revolutions of 1848. Political Writings. v.1. Trad. David Fernbach. Harmondsworth: Penguin, 1973, p.77.

${ }^{12}$ Grundrisse, p.464.

${ }^{13}$ MARX, Karl. Theorien über den Mehrwert. In: Marx-Engels Werke. v.26/3, p.414.

${ }_{14}$ Manifesto of the Communist Party. Op. cit., p.75.

${ }^{15} \mathrm{Idem}$, p.77. Sobre a conceituação dos produtores de pequenas mercadorias em Marx ver também o apêndice em JAEGER, Christine. Artisanat et capitalisme: l'envers de la roue de l’histoire. Paris: Payot, 1982, p.297-314. 
${ }^{16}$ Capital, v.I, p.797. Compare The Class Struggles in France, 1848-1850: "uma massa nitidamente diferenciada do proletariado industrial, uma fonte de recrutamento para ladrões e criminosos de todos os tipos, vivendo das migalhas da sociedade, pessoas sem um ofício definido, vagabundos, gens sans feu et sans aveu". Marx and Engels, Selected Works, v.I. Moscow: 1951, p.142. Ver também HAYES, Peter. Utopia and the Lumpenproletariat: Marx’s Reasoning in The Eighteenth Brumaire of Louis Bonaparte. Review of Politics, p.445-465, 1988. Diferentes visões sobre a posição das prostitutas no sistema de classe podem ser encontradas nos escritos de Marx. Quando ele discute a população geradora de mais-valia relativa em $O$ Capital, ele vê as prostitutas como uma parte importante do "lumpem-proletariado real" (Capital, I, 797) Em outras partes, especialmente nas Teorias da mais-valia, Marx diz que as prostitutas, se elas trabalham para um proprietário de bordel, desempenham trabalho assalariado improdutivo, como atores ou músicos e assim são, por decorrência, parte do proletariado no sentido estrito da palavra (Marx-Engels Werke [MEW], v.26/1, p.136, 157). Isso demonstra uma vez mais que os modos pelos quais as classes sociais são definidas são repletos de falsas considerações, que freqüentemente permanecem implícitas, precisamente porque elas são moralistas e características do seu tempo. É a isso provavelmente que Resnick e Wolff se referem como um "instrumento discursivo" inspirado por uma "intenção polêmica urgente". RESNICK, Stephen A. \& WOLFF, Richard D. Knowledge and Class. A Marxian Critique of Political Economy. Chicago/Londres: University of Chicago, 1987, p.161-162.

${ }^{17}$ RAMSEYER, J. Mark. Indentured Prostitution in Imperial Japan: Credible Commitments in the Commercial Sex Industry. The Journal of Law, Economics, and Organization, n.7, p.89-116, aqui 101, 1991.

18 JOHNSON, Lyman L. The Competition of Slave and Free Labor in Artisanal Production: Buenos Aires, 1770-1815. In: BRASS, Tom \&LINDEN, Marcel van der (org.). Free and Unfree Labour: The Debate Continues. Berne: Peter Lang Academic Publishers, 1997, p.265-280, aqui 273.

${ }^{19}$ BOLLAND, O. Nigel. Proto-Proletarians? Slave Wages in the Americas. In: TURNER, Mary (org.). From Chattel Slaves to Wage Slaves: The Dynamics of Labour Bargaining in the Americas. Kingston: Ian Randle, 1995, p.123-147, 128.

${ }^{20}$ Idem, p. 127.

${ }^{21}$ TURNER, Mary. Chattel Slaves into Wage Slaves: A Jamaican Case Study. In: . From Chattel Slaves to Wage Slaves, p.33-47, aqui 39.

${ }^{22}$ ASHTON, T. S. The Coal-Miners of the Eighteenth Century. The Economic Journal: Economic History Series, n.3, jan., 1928, p.307-334, aqui 308.

${ }^{23}$ Ver a resenha em POTTS, Lydia. The World Labour Market. A History of Migration. London: Zed Books, 1990.

${ }^{24}$ Ver o exemplo das cigarreiras cubanas na década de 1850 em CASANOVAS, 
Joan. Bread, or Bullets! Urban Labor and Spanish Colonialism in Cuba, 1850-1898. Pittsburgh: University of Pittsburgh, 1998, p.60.

25 ORCHARD, John E. Japan's Economic Position: The Progress of Industrialization. London: McGraw-Hill, 1930, p.343.

${ }^{26}$ THOMPSON, Ruth. Trade Union Organisation: Some Forgotten Aspects. In: ADELMAN, Jeremy (ed.). Essays in Argentine Labour History, 1870-1930. Houndmills and London: Macmillan, 1992, p.160-176, aqui 161.

${ }^{27}$ A compra do produto pelo empregador ocorria de acordo com PARPART, Jane L. Labor and Capital on the African Copperbelt. Philadelphia: Temple University, 1983, p.42, nas minas de cobre da Rodésia Setentrional na década de 1930.

${ }^{28}$ WALTERSHAUSEN, August Sartorius von. The Workers' Movement in the United States, 1879-1885. Org. David Montgomery e Marcel van der Linden. New York: Cambridge University, 1998, p.216.

${ }^{29}$ MCDONALD JR., Angus W. The Urban Origins of Rural Revolution: Elites and the Masses in Hunan Province, China, 1911-1927. Berkeley: University of California, 1978, p.147. Hoje em dia, um arranjo similar ainda existe no caso de motoristas de jipes e táxis em Manila. Ver PINCHES, Michael. "'All that we have is our muscle and sweat'. The Rise of Wage Labour in a Manila Squatter Community". In: PINCHES, Michael \&LAKHA, Salim (org.). Wage Labour and Social Change: The Proletariat in Asia and the Pacific. Monash: University, Centre of Southeast Asian Studies, 1987, p.103-136, aqui 118.

${ }^{30}$ AVILA, Cuauhtemoc Velasco. Labour Relations in Mining: Real del Monte and Pachuca, 1824-74. In: GREAVES, Thomas \& CULVER, William (org.). Miners and Mining in the Americas. Manchester: Manchester University, 1985, p.47-67, aqui 57.

${ }^{31}$ Ver, por exemplo, HART, Gillian. Power, Labor, and Livelihood: Processes of Change in Rural Java. Berkeley: University of California, 1986, p.180-182; HÜSKEN, Frans. Landlords, Sharecroppers and Agricultural Labourers: Changing Labour Relations in Rural Java. Journal of Contemporary Asia, n.9, p.140-151, 1979.

${ }^{32}$ MOORE, John Hebron. Simon Gray, Riverman: A Slave Who Was Almost Free. The Mississippi Valley Historical Review, n.49, p,472-484, dec., 1962; republicado em: NEWTON, James E. \& LEWIS Ronald L. (org.). The Other Slaves: Mechanics, Artisans and Craftsmen. Boston, MA: G.K. Hall \&Co., 1978, p.157-67, aqui 158-59.

33 TURNER, Mary. Chattel Slaves into Wage Slaves: A Jamaican Case Study. In: From Chattel Slaves to Wage Slaves, p.33-47, aqui 34.

${ }^{34}$ ALLEN, V. L. The Meaning of the Working Class in Africa. Journal of Modern African Studies, v.10, n.2, 1972, p.169-189, aqui 188.

35 BERNSTEIN, Irving. The Lean Years. A History of the American Worker, 1920-1933. Boston, 1960, p.422. 
${ }^{36}$ COLLONGES, Yann \& RANDAL, Pierre Georges. Les autoréductions. Grèves d'usagers et luttes de classes en France et en Italie (1972-1976). Paris: 10/18, 1976, cap.4.

${ }^{37}$ ADAMIC, Louis. The Great 'Bootleg' Coal Industry. The Nation, n.40, 1935, p.46. Uma descrição de acontecimentos similares na Silésia Superior aparece em: MACHTAN, Lothar. "Die 'Elendsschächte' in Oberschlesien: Bergmännische Selbsthilfe-Initiativen zur Überwindung von Arbeitslosigkeit um 1930". Jahrbuch Arbeiterbewegung Geschichte und Theorie 1982. Frankfurt/Main: Eva, 1982, p.141-155.

${ }^{38}$ DITTON, Jason. "Perks, Pilferage, and the Fiddle: The Historical Structure of Invisible Wages". Theory and Society, n.4, 1977, p.39-71. Estudos de caso incluem: MARS, Gerald. "Dock Pilferage: A Case Study in Occupational Theft". In: ROCK, Paul \&MCINTOSH, Mary (org.). Deviance and Social Control. London, 1974, p.209-228 GRÜTTNER, Michael. Working-Class Crime and the Labour Movement: Pilfering in the Hamburg Docks, 1888-1923. In: EVANS, Richard J. (org.). The German Working Class 1888-1933. The Politics of Everyday Life. London and Totowa: Croom Helm and Barnes \&Noble, 1982, p.54-79; D'SENA, Peter. Perquisites and Casual Labour on the London Wharfside in the Eighteenth Century. London Journal, n.14, 1989, p.130-147; RANDALL, Adrian J. Peculiar Perquisites and Pernicious Practices. Embezzlement in the West of England Woollen Industry, c. 1750-1840. International Review of Social History, n.35, p.193-219, 1990; GREEN, Anna. Spelling, Go-Slows, Gliding Away and Theft: Informal Control over Work on the New Zealand Waterfront, 1915-1951. Labour History, n.63, p.100-114, 1963; SMYTH, Ines \& GRIJNS, Mies. Unjuk Rasa or Conscious Protest? Resistance Strategies of Indonesian Women Workers. Bulletin of Concerned Asian Scholars, v.29, n.4, 1997, p.13-22, aqui 21. William Freund revela a possibilidade de uma transição suave ao roubo como ação coletiva em "Theft and Social Protest Among the Tin Miners of Northern Nigeria". Radical History Review, n.26, 1982, p.68-86.

${ }^{39}$ A literatura sobre esse tema é tão gigantesca que nos limitamos a mencionar um trabalho representativo: WALBY, Sylvia. Patriarchy at Work. Patriarchal and Capitalist Relations in Employment. Cambridge: Polity, 1986.

40 EVERS, Hans-Dieter. "Schattenwirtschaft, Subsistenzproduktion und informeller Sektor“. In: Klaus Heinemann (org.), Soziologie wirtschaftlichen Handelns. Opladen: Westdeutscher Verlag, 1987, p.353-366, aqui 360.

${ }^{41}$ ONSELEN, Charles van. Studies in the Social and Economic History of the Witwatersrand, 1886-1914. v.2: New Nineveh. Harlow: Longman, 1982, p.3031 .

${ }^{42}$ Sobre o sistema de barracão ver por exemplo: HILTON, George W. The Truck System Including a History of the British Truck Acts, 1465-1960. Cambridge, 1960. 
43 Estudos sobre moradia proporcionada pelas empresas incluem: AGGARWAL, S. C. Industrial Housing in India. Nova Déli, 1952; TIPPLE, A. Graham. Colonial Housing Policy and the "African Towns" of the Copperbelt: The Beginnings of Self-Help. African Urban Studies, n.11, 1981, p.65-85; MELLING, Joseph. Employers, Industrial Housing and the Evolution of Company Welfare Politics in Britain's Heavy Industries: West Scotland, 18701920. International Review of Social History, n.26, p.255-301, 1981; HONHART, Michael. Company Housing as Urban Planning in Germany, 1870-1940. Central European History, n.23, p.3-21, 1990; CRINSON, Mark. Abadan: Planning and Architecture under the Anglo-Iranian Oil Company. Planning Perspectives, n.12, p.341-359, 1997;

${ }^{44}$ HUSSEY, Stephen. Low Pay, Underemployment and Multiple Occupations: Men's Work in the Inter-war Countryside. Rural History, n.8, p.217-235, 1997; KLOPOV, Eduard V. Secondary Employment as a Form of Social and Labor Mobility. Sociological Research, v.37, n.2, march-april, 1998, p.64-87.

${ }^{45}$ FRANK, André Gunder. Capitalism and Underdevelopment in Latin America: Historical Studies of Chile and Brazil. ed. rev. e exp. Nova Iorque: Monthly Review, 1969, p.271-272.

46 "Em anos de fartura, os criados freqüentemente deixam os seus mestres, e confiam sua subsistência ao que eles podem produzir por sua própria iniciativa. [...] Em anos de escassez, as dificuldades e incertezas da subsistência deixam todas essas pessoas ansiosas por retornar ao serviço.” SMITH, Adam. The Wealth of Nations. Londres: Everyman's Library, 1991, p.74.

47 CHESNEAUX, Jean. Chinese Labor Movement 1919-1927. Trad. H. M. Wright. Stanford: Stanford University, 1968, p.57.

48 SIMEON, Dilip. The Politics of Labour Under Late Colonialism: Workers, Unions and the State in Chota Nagpur, 1928-1939. Nova Déli: Manohar, 1995, p.25-26; WRIGHT, Tim. "A Method of Evading Management" Contract Labor in Chinese Coal Mines before 1937. Comparative Studies in Society and History, n.23, 1981, p.656-678.

49 MIXTER, Timothy. The Hiring Market as Workers' Turf: Migrant Agricultural Workers and the Mobilization of Collective Action in the Steppe Grainbelt of European Russia, 1853-1913. In: KINGSTON-MANN, Esther \& MIXTER, Timothy (org.). Peasant Economy, Culture, and Politics of European Russia, 1800-1921. Princeton: Princeton University, 1991, p.294-340.

50 MARTIN, Cheryl English. Governance and Society in Colonial Mexico: Chihuahua in the Eighteenth Century. Stanford, CA: Stanford University, 1996 , p.51.

51 SCHULER, Monica. "Akan Slave Rebellions in the British Carribean". Savacou, 1, 1, jun., 1970. Reimpresso em: Hilary Beckles e Verene Shepherd (org.). Caribbean Slave Society and Economy: a student reader. Kingston e Londres, 1991, p.373-386, aqui p.382-383. 
52 Corretamente, Cloward e Fox Piven destacam: "[...] algumas formas de protesto são mais ou menos universalmente disponíveis. Ataques incendiários, seja nos campos do mundo pré-industrial ou nas ruas do mundo urbanizado, requer mais recursos tecnológicos do que organizacionais e de todo modo não muito dos primeiros. Motins requerem pouco em termos de organização do que de número, cumplicidade, e alguma comunicação. A maioria dos assentamentos humanos, seja as aldeias pré-industriais ou as metrópoles modernas, suprem esses requerimentos estruturais." PIVEN, Frances Fox \& CLOWARD, Richard A. Collective Protest: A Critique of Resource-Mobilization Theory. In: LYMAN, Stanford M. (org.). Social Movements: critiques, concepts, case-studies. Houndmills: Macmillan, 1995, p.137-167, aqui p.148.

${ }^{53}$ Para uma argumentação plena ver as minhas "Introdução" e "Conclusão" em KOK, Jan (org.). Rebellious Families. Household Strategies and Collective Action in the Nineteenth and Twentieth Centuries. Oxford e Nova Iorque: Berghahn, 2002, p.1-23 e p.230-242.

${ }^{54}$ CASTORIADIS, Cornelius. The Imaginary Institution of Society. Trad. Kathleen Blamey. Cambridge: Polity, 1987, p.109.

${ }^{55}$ COHEN, G. A. Karl Marx's Theory of History: a defence. Oxford: Clarendon, 1978 , p.72.

56 O conceito de "compulsão econômica" por exemplo, merece maior consideração porque ele envolve uma dimensão coletiva importante. Mesmo se cada proletário individual pode, em teoria, escapar do seu destino pela mobilidade ascendente, ainda pode haver compulsão coletiva e falta de liberdade, porque "cada [proletário] apenas é livre sob condição de que outros não exercitem sua liberdade similarmente condicional”. COHEN, G. A. History, Labour, and Freedom. Themes from Marx. Oxford: Clarendon, 1988, p.263.

57 MARX, Capital, I, p.284. Ver também WITTFOGEL, Karl August. "Geopolitik, geographischer Materialismus und Marxismus". Unter dem Banner des Marxismus, n.3, p.17-51, p.485-522, p.699-735, aqui p.506-522, 1929, e BALIBAR, Etienne. "Sur les concepts fondamentaux du matérialisme historique”. In: ALTHUSSER, Louis. et al., Lire le Capital. v.II. Paris: Maspéro, 1968, p.79-226, aqui 98 .

${ }^{58}$ Naturalmente, as dimensões podem se sobrepor. No setor de serviços, por exemplo, os meios de trabalho e o produto do trabalho podem ser idênticos e na subcontratação a equipe de trabalho consiste em membros do núcleo doméstico.

${ }^{59}$ Vendo os trabalhadores subalternos como heteronomia institucionalizada, podemos dizer que o grau de heteronomia é maior à medida que o empregado ou a empregada possui menos poder sobre (i) sua própria capacidade de trabalho, (ii) meio de trabalho, (iii) produtos do trabalho, (iv) os companheiros membros do seu próprio núcleo doméstico, (v) a relação com o empregador 
fora do processo de trabalho imediato, e (vi) possíveis colegas de trabalho no processo de trabalho. Nesse sentido, as mulheres geralmente têm menos autonomia do que os homens e a autonomia dos assalariados é maior do que a autonomia dos escravos, mas menor do que a autonomia dos trabalhadores empregados por conta própria.

${ }^{60}$ Para uma discussão do problema de "famílias policlassistas" ver: GRAETZ, Brian. The Class Location of Families: A Refined Classification and Analysis. Sociology, n.25, p.101-118, 1991. Graetz propôs um "modelo genérico para a classificação conjunta de posições de classe familiares".

${ }^{61}$ Por razões subjetivas, nem todo mundo muda o seu tipo de relação de trabalho facilmente. Quando o cientista social norte-americano Bakke viveu no bairro operário de Greenwich (Londres) no começo da década de 1930, ele observou uma "falta de motivação para se lançar a algum tipo de empreendimento independente". Ele explicou isto pela "inabilidade daqueles que foram nascidos e criados na tradição do assalariado de visualizarem a si mesmos como trabalhadores independentes, seus próprios chefes". Essa "falta de imaginação" resultava da socialização do assalariado no trabalho: "A rotina de trabalho, a regularidade e a simplicidade da rotina fora do horário de trabalho, as necessidades elementares da economia doméstica", tudo isso reforçando "uma disciplina que treina para a estabilidade como um assalariado, mas não para a independência e adaptabilidade e personalidade necessária para o sucesso em um empreendimento independente.” BAKKE, E. Wight. The Unemployed Man: A Social Study. London: Nisbet and Co., 1935, p.126-127.

${ }^{62}$ WALLERSTEIN, Immanuel. Class Conflict in the Capitalist World-Economy. In:_. The Capitalist World-Economy. Cambridge e Paris: Cambridge University e Editions de la Maison des Sciences de l'Homme, 1979, p.283-293, aqui p.289-290. A abordagem de Wallerstein como tal certamente não é adequada porque a sua categoria "proletário" se reduz a "a mais geral e portanto a mais abstrata determinação de classe" "a apropriação do produto da mais-valia" e é imposta de fora sobre as mais diversas relações sociais. As classes são definidas em relação ao produto do seu trabalho, antes do que pela sua relação umas com as outras no seu processo de produção e reprodução social. É como se as relações das pessoas com as coisas é que fossem decisivas, ao invés das relações delas umas com as outras. TOMICH, Dale. "World of Capital / Worlds of Labor: A Global Perspective”. In: HALL, John R. (ed.). Reworking Class. Ithaca, NY: Cornell University, 1997, p.287-311, aqui 290.

${ }^{63} \mathrm{O}$ trabalho dos economistas políticos Robert W. Cox e Jeffrey Harrod também pode se comprovar estimulante. Ver o artigo programático de Cox, "Approaches to a Futurology of Industrial Relations", International Institute of Labour Studies Bulletin (1971), n.8, p.139-164, e a elaboração do seu trabalho em dois livros: Cox, Production, Power and World Order: Social Forces in the 
Making of History. Nova Iorque: Columbia University, 1987, e Harrod, Power, Production, and the Unprotected Worker. Nova Iorque: Columbia University, 1987.

${ }^{64}$ MINTZ, Sidney W. Was the Plantation Slave a Proletarian? Review, v.2, n.1, summer, 1978, p.81-98, aqui p.97-98.

Artigo recebido em 02/2006. Aprovado em 04/2006. 